\title{
Genetic control of the renal clearance of urate: a study of twins
}

\author{
B T Emmerson, S L Nagel, D L Duffy, N G Martin
}

\begin{abstract}
Although a genetic predisposition to gout has been recognised for centuries, its mechanism has never been defined. This study was designed to determine whether this factor might be the renal clearance of urate, which is an important determinant of the concentration of urate in serum. In this study the renal clearance of urate was examined in $\mathbf{3 7}$ pairs of normouricaemic twins to determine whether this resemblance was genetically mediated. Monozygotic twins had more similar values of urate clearance and fractional excretion of urate than dizygotic twins. The heritability of the renal clearance of urate was estimated as about $60 \%$ (95\% confidence limits 40 to $100 \%$, whereas the heritability of the fractional excretion of urate was $87 \%$ (confidence limits 45 to $100 \%$ ). This study supports the hypothesis that genetic factors exert an important control on the renal clearance of urate, which determines some of the familiality of hyperuricaemia and gout.
\end{abstract}

Hyperuricaemia has been shown in numerous studies to cluster within families. ${ }^{1-3}$ Shared genes and shared environment (especially diet) have been implicated in this process. Although defective (decreased) urate excretion is known to underlie a significant number of cases of hyperuricaemia, ${ }^{4}$ only a few studies have specifically examined the genetics of the renal clearance of urate. Scott and Pollard ${ }^{5}$ examined the 24 hour urinary excretion and clearance of urate in relatives of hyperuricaemic probands and normouricaemic controls. Urate clearance and the urate:creatinine clearance ratio were correlated between probands and the relatives of the subjects. These authors noted that this type of design cannot distinguish genetic and environmental determinants. In this study, we have used the classical twin design to examine the heritability of the renal clearance of urate in a small sample of healthy twins from Queensland, Australia.

\section{Patients and methods}

Invitations to take part in this study were sent to all complete adult twin pairs resident in Brisbane, Queensland, and registered with the Australian National Health and Medical Research Council Twin Registry. This is a volunteer based registry whose members were recruited by media advertising, community groups, and school visits. Throughout Australia, it consisted in 1980 of 5967 pairs of adult twins. However, there were only 176 pairs where both adults were resident in Brisbane. Of these, there were 25 monozygotic pairs and 12 dizygotic pairs who were able to take part. None had had gout.

Zygosity was determined by questionnaire ${ }^{6}$ and confirmed in 13 pairs by blood typing for the ABO, Rh, Fy, Kell, Jk, MNS, $P_{1}$, and Le systems. There were no inconsistencies between the two methods in these twins.

Urate and creatinine clearances were estimated in these healthy subjects while they were receiving their normal diet. None was taking any drugs nor showed evidence of renal disease. All clearance estimations were performed in the morning with the patient fasting following an initial water load of $500 \mathrm{ml}$ and a continuing intake of $150 \mathrm{ml}$ of water every 30 minutes to maintain a water diuresis. ${ }^{7}$ Urine was collected at 30 minute intervals on three occasions. These high urine flow rates facilitated bladder emptying and provided more reliable clearance values. Clearances at such high flow rates often yield values considerably higher than those calculated from 24 hour collections. ${ }^{7}$ Venepuncture was performed at the midpoint of the first and third collection periods: Serum and urinary creatinine concentrations were determined by an autoanalyser (Technicon); serum and urinary urate were determined using an automated modification of the differential spectrophotometric uricase method. ${ }^{8}$ The urate and creatinine clearances (in $\mathrm{ml} / \mathrm{min}$ ) for the three time intervals were calculated by the formula:

$$
\text { Clearance }(\mathrm{ml} / \mathrm{min})=\frac{\text { urinary excretion in unit time }(\mu \mathrm{mol} / \mathrm{min})}{\text { plasma concentration }(\mu \mathrm{mol} / \mathrm{ml})}
$$

Another measurement of the renal handling of urate is the fractional excretion of urate, calculated as the percentage ratio of the urate and creatinine clearances. This effectively cancels out the urine flow rate component from the two estimations as it is the same for simultaneous measurements of these clearances.

To allow for variations of body size, all clearances were corrected to a standard body surface area of $1.73 \mathrm{~m}^{2}$.

Selected descriptive statistics were generated using SPSS-PC (SPSS Inc). Pearson's correlations between one twin (arbitrarily designated twin 1) and the co-twin (twin 2) in the monozygotic and dizygotic groups were calculated for the measured and calculated values. As monozygotic twins are genetically identical, whereas dizygotic twins on average share only $50 \%$ of their genes identical by descent, it would be expected that the monozygotic intertwin correlation would be higher than the dizygotic 
correlation if genes exert an influence on the trait in question. Therefore, we initially tested the null hypothesis that the monozygotic and dizygotic correlations were equal with bootstrapped standard errors derived using PRELIS $2 .{ }^{10}$ Using the results and methods of genetic path analysis, ${ }^{11}$ the variance of the trait was further partitioned into that due to an additive genetic variation $\left(h^{2}\right)$, shared or family environment $\left(c^{2}\right)$, and unique or unshared environmental influences $\left(\mathrm{e}^{2}\right)$. A commonly cited summary measure is the 'broad' heritability, representing that proportion of the total variance under the control of genetic influences $\left(h^{2} / V_{T}\right)$. This path modelling has been performed with the structural equation modelling package LISREL $7 \cdot 16 .{ }^{12}$ It should be noted that the maximum likelihood derived results here are likely to be biased in such a small sample, and should be regarded with caution.

\section{Results}

The mean age of the subjects recruited was 36 years (range 13-59). There were 37 men and 37 women. The serum urate concentration was significantly higher in the men than in the women $(0.36 v 0.29, \mathrm{p}<0.001)$. The mean creatinine clearance was $124 \mathrm{ml} / \mathrm{min}$ (range 43-199) and the mean urate clearance 10.0 $\mathrm{ml} / \mathrm{min}$ (range $4 \cdot 4-22 \cdot 2$ ). There was a highly significant correlation between any two of the clearance estimations in any subject $(r=0.81$ for urate, 0.71 for creatinine, and 0.96 for the fractional excretion of urate). The data did not show any significant sex differences for urate and creatinine clearance, either corrected or uncorrected to the standard surface area, although a larger study group may have allowed such differences to be detected. As a result, the sexes have been pooled for genetic analyses. The Kolmogorov-Smirnov one sample test for normality suggested that tnese results came from a normal population $(p=0 \cdot 24)$.

Table 1 Monozygotic and dizygotic intertwin correlations for urate and creatinine clearances corrected to a standard surface area of $1.73 \mathrm{~m}^{2}$

\begin{tabular}{lll}
\hline \multirow{2}{*}{ Trait } & \multicolumn{2}{l}{$\begin{array}{l}\text { Correlation coefficient (bootstrapped 95\% } \\
\text { CI })^{*}\end{array}$} \\
\cline { 2 - 3 } & Monozygotic & Dizygotic \\
\hline $\begin{array}{l}\text { Creatinine clearance } \\
\begin{array}{l}\text { Urate clearance } \\
\text { Fractional excretion } \\
\text { of urate }\end{array}\end{array}$ & $\begin{array}{l}0.80(0.33 \text { to } 0.92) \\
0.85(0.65 \text { to } 0.94)\end{array}$ & $\begin{array}{l}0.55(-0.32 \text { to } 0.86) \\
0.15 \text { to } 0.86)\end{array}$ \\
\hline *The bootstrapped confidence intervals $(\mathrm{CI})$ were calculated
\end{tabular}

using the algorithm presented by Efron and Tibshirani..$^{14}$

Table 2 Proportional variance explained by each factor and tests of model fit for path analysis of the clearance of urate. The value $h^{2}$ refers to the additive genetic variation, $c^{2}$ to shared or family environment, and $e^{2}$ to unshared environmental influences (see text)

\begin{tabular}{|c|c|c|c|c|c|c|c|}
\hline Model & $h^{2}(\%)$ & $c^{2}(\%)$ & $e^{2}(\%)$ & Age & $x^{2}$ & $\begin{array}{l}\text { Degrees of } \\
\text { freedom }\end{array}$ & $p$ Value \\
\hline $\begin{array}{l}\text { Model 1: additive genes and } \\
\text { common environment } \\
\text { Model 2: additive genes* } \\
\text { Model 3: shared environment }\end{array}$ & $\begin{array}{l}58 \\
69 \\
-\end{array}$ & $\frac{12}{59}$ & $\begin{array}{l}17 \\
16 \\
26\end{array}$ & $\begin{array}{l}14 \\
14 \\
14\end{array}$ & $\begin{array}{l}1 \cdot 74 \\
0 \cdot 84 \\
6 \cdot 21\end{array}$ & $\begin{array}{l}3 \\
2 \\
2\end{array}$ & $\begin{array}{l}0.63 \\
0.40 \\
0.04\end{array}$ \\
\hline
\end{tabular}

*The fit of model 2 is not significantly less than the 'full' model $1\left(\chi^{2}=0.1, p=0.75\right)$. The fit of model 3 is significantly worse than that of model $1\left(x^{2}=4 \cdot 74, p=0.03\right)$, therefore it is rejected. Therefore model 2 is chosen as the most parsimonious model.

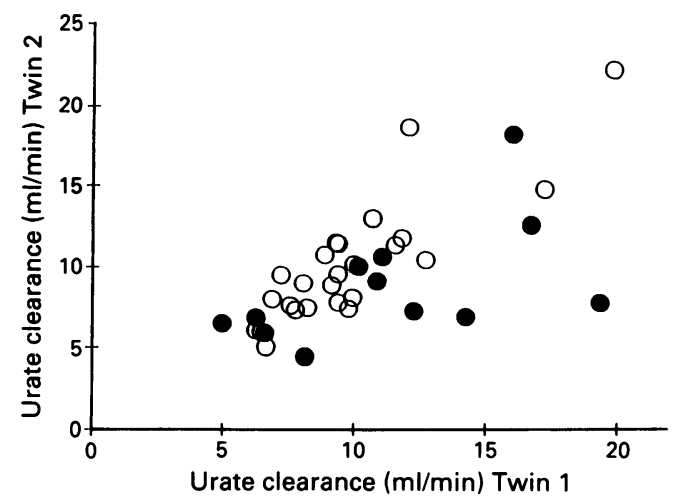

Figure 1 Renal clearances of urate in one twin plotted against those for the second twin for dizygotic and monozygotic twin pairs. All clearances are corrected to a standard body surface area of $1 \cdot 73 / \mathrm{m}^{2}$.

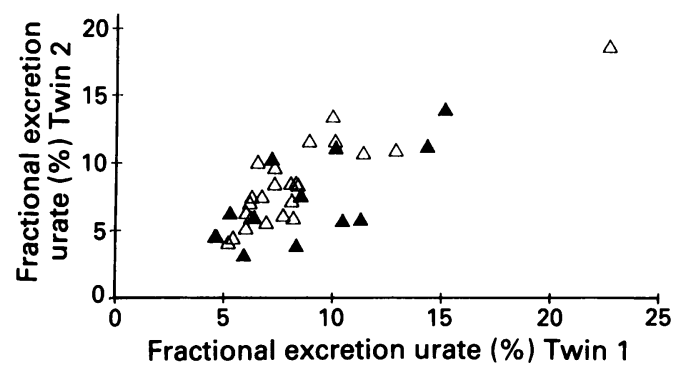

Figure 2 Fractional excretion of urate in one twin plotted against that for the second twin for dizygotic and monozygotic twin pairs.

Figures 1 and 2 show the urate clearances and the fractional excretion of urate in the monozygotic and dizygotic twins respectively. Table 1 shows the intertwin correlations for urate and creatinine clearances and the fractional excretion of urate. Monozygotic twins gave more concordant results than dizygotic twins. These differences attained significance for the clearance of urate (Fisher $\mathrm{Z}$ test, $\mathrm{p}=0.04$ ), but not for the clearance of creatinine $(p=0 \cdot 10)$. The fractional excretion of urate was also significantly more concordant in the monozygotic than in the dizygotic twins (table 1, fig 2). These conclusions were unchanged by the exclusion from the calculations of the most extreme data point.

Table 2 presents the LISREL models for urate clearance. A genetic contribution to twin resemblance is confirmed, with the heritability of the urate clearance being estimated at $69 \%$ $(p=0.02)$. With such a small sample size, the standard confidence limits of the heritability are fairly wide at 40 to $100 \%$, but do not include zero. The heritability of the fractional excretion of urate was $87 \%(p=0.04)$ with confidence limits of 45 to $100 \%$. A role for shared environmental effects was not supported in this data set, but again the confidence limits are very wide.

\section{Discussion}

The normal renal urate clearance shows an important amount of individual variation (25\% 
coefficient of variation) and clinical studies suggest that a low urate clearance may underlie many cases of hyperuricaemia and gout. ${ }^{5}$ The present results suggest that this variation is partly under genetic control. Earlier twin studies have found serum urate concentrations to have a heritability of approximately $70 \% .^{13}$ None, however, have examined urate excretion. In the previously mentioned family study of Scott and Pollard, ${ }^{5}$ all classes of relatives were combined as the number of parents and offspring was small, and no measurement of relevant family environment was attempted, so that genetically meaningful analyses were limited. Interestingly, the dizygotic or sib-sib correlation for the clearance of urate of 0.70 which we observed is similar to that $\left(r_{\text {male }}=0.77 ; r_{\text {female }}=0.49\right)$ cited by Scott and Pollard ${ }^{5}$ for the correlation seen among hyperuricaemic probands and their pooled male relatives $(85 \%$ of whom were siblings). This gives some indirect support to the present results.

This study showed a wide range of ages and clearances in the normal healthy twins studied. Some of this may be attributed to the high urine flow rate used in the clearance measurements and by the correction of the results to a standard surface area. However, as the principal analysis was comparing one twin with the second twin of the same age and with the same water load, the effect of these factors on the results would have been minimal. Moreover, no effect of age on the results could be shown. It should be recalled that the relatively small sample size in this study has forced us to collapse across sex, an important covariate of serum urate concentrations, though not always of the urate clearance in this or other studies. ${ }^{5}$ A replication of the present findings in a larger study, either an appropriately designed family or twin study, is needed. Finally, a quantitative trait may appear normally distributed in the population and still be under the control of a major gene, but masked by continuous environmental variation. Modern segregation analysis of family data is needed to test this hypothesis.

1 Smyth C J, Cotterman C W, Freyberg R H. The genetics of gout and hyperuricaemia - an analysis of nineteen families. gout and hyperuricaemia- an

2 Hauge $M$, Harvald $B$. Heredity in gout and hyperuricaemia. Acta Med Scand 1955; 152: 247-57.

3 Boyle J A, Greig W R, Jasani M K, Duncan A, Diver M. Buchanan WW. Relative roles of genetic and environmental factors in the control of serum uric acid levels in normouricaemic subjects. Ann Rherum Dis 1967; 26: 234-7.

4 Rieselbach R E, Sorensen L B, Shelp W D, Steele T H. Diminished renal urate secretion per nephron as a basis for primary gout. Ann Intern Med 1970; 73: 359-66.

5 Scott JT, Pollard AC. Uric acid excretion in the relatives of patients with gout. Ann Rheum Dis 1970; 29: 397-400

6 Kasriel J, Eaves L J. The zygosity of twins: further evidence on the agreement between diagnosis by blood groups and written questionnaires. $\mathcal{F}$ Biosoc $S c i$ 1976; 8: 263-6.

7 Richardson J A, Philbin P E. The one-hour creatinine clearance rate in healthy men. $\mathscr{F} A M A$ 1971; 216: 987-90.

8 Liddle L, Seegmiller J E, Laster L. The enzymatic spectrophotometric method for determination of uric acid. $\mathcal{f} \mathrm{Lab}$ Clin Med 1959; 54: 903-14.

9 McIntosh J F, Moller R, Van Slyke D D. Study of urea excretions: the influence of body size on urea output. $\mathcal{F}$ Clin Invest 1928; 6: 467.

10 Joreskog K G, Sorbom D. PRELIS users' guide. 1st ed. Moorsville: Scientific Software, 1986.

11 Heath A C, Neal M C, Hewitt J K, Eaves L J, Fulker D W. Testing structural equation models for twin data using LISREL. Behav Genet 1989; 19: 9-35.

12 Joreskog K G, Sorbom D. LISREL 7. A guide to the program and applications. 2nd ed. Chicago: SPSS, 1989.

13 Whitfield J B, Martin N G. Inheritance and alcohol as factors influencing plasma uric acid levels. Acta Genet Med Gemellol (Roma) 1983; 32: 117-26.

14 Efron B, Tibshirani R. Bootstrap methods for standard errors, confidence intervals, and other measures of statistical accuracy. Statistical Science 1986; 1: 54-77. 